\title{
An Experimental Study on the Teenagers' Music Cognition and Acquisition Process Based on App Music Game
}

\author{
Yi Ji \\ Music and Dance College \\ Qujing Normal University \\ Qujing, Yunnan, China
}

\begin{abstract}
App music game has become a significant field and effective way for teenager to obtain music knowledge and apply musical ability. In order to realize teenagers characteristics and acquisition process based on the App music game music cognitive process, and our current music education system in middle school to explore, the adolescents (12-14 years old) as the object studied the stage with music game App music and its acquisition process based on cognitive research the content in the basic knowledge and skills, processes and methods, emotional experience, physiological and psychological characteristics of the four aspects of the validity and reliability of higher hierarchical measurement problem to research conclusions of the study that App music games on Youth Music cognitive vision broadening and musical ability development has a positive effect.
\end{abstract}

Keywords-App; music games; teenager; music cognition; acquisition process

\section{INTRODUCTION}

App is the abbreviation of Application, based on the development of iPhone and other smart phones, App refers to the smart phone's third party applications. Mobile App shows its convenience and practicability, as well as its rich and powerful application software for the majority of users to bring the greatest practical and entertaining. Researchers estimate that Chinese intelligent mobile phone users will reach 400 million in 2014, accounting for more than a quarter of the number of mobile phone users. App music game has been valued by App developers because of its strong attraction, diverse forms and rich contents. At the same time, music educators and music psychologists are also concerned about its impact on school music education and youth music cognition, especially paying attention to the music cognition and acquisition process based on App music game. Many music educators and psychology researchers expect young people's music cognition and acquisition from their school music education, especially thinking that young people who are in physical and psychological development should acquire music cognition and keep certain ability of music application from middle school music education. In fact, foreign researcher, Haq Cihan, showed that with the growth of age, the exposure of music ability is gradually reduced (as shown in "Table I"). Therefore, it is necessary to carry out active and effective guidance according to physical and psychological characteristics of young people and new media social environment factors of music cognition and acquisition, in order to compensate for teenagers because music ability to manifest decreases causing of music cognition and the negative influence of the applied force. In particular, added guidance and attention of App music game will play an important role in youth music cognition, its acquisition expanded and comprehensive development of music ability. So, what are the characteristics and how to realize the music cognition and acquisition process of teenagers' participation in App music games? What is the effectiveness of the current secondary school music education system in our country? These problems are basically no systematic experimental study. In order to explore the above issues, the author picked the youth (12-14 years old) as the object to carry out the experimental study in music cognition and the acquisition process of App music game young people involved.

TABLE I. AgE Distribution OF MUSIC Al ABILIT Y

\begin{tabular}{|c|c|c|c|c|c|c|c|c|}
\hline Age & $\begin{array}{l}\text { Before } 3 \\
\text { years old }\end{array}$ & $\begin{array}{l}\text { 3-5 years } \\
\text { old }\end{array}$ & $\begin{array}{l}6-8 \text { years } \\
\text { old }\end{array}$ & $\begin{array}{l}9-11 \\
\text { years old }\end{array}$ & $\begin{array}{l}12-14 \\
\text { years old }\end{array}$ & $\begin{array}{l}15-17 \\
\text { years old }\end{array}$ & $\begin{array}{l}18 \text { and } \\
\text { over }\end{array}$ & total \\
\hline Male & 22.4 & 27.3 & 19.5 & 16.5 & 10.7 & 2.4 & 1.2 & $100 \%$ \\
\hline Female & 31.5 & 21.8 & 19.1 & 16.6 & 6.5 & 1.0 & 0.5 & $100 \%$ \\
\hline
\end{tabular}




\section{EXPERIMENTAL METHOD}

\section{A. Participants}

Participants from a middle school junior high school (1214 years old) student volunteer enrollment, provide 2 kinds of registration options: often participate in App music games and never participate in. In the enrollment of students randomly selected 30 people divided into experimental group and control group, each group of 15 people, and the experimental group was divided into 8 men and 7 women, the establishment of the experimental effective survey for 30 people. All subjects had no physiological abnormalities.

\section{B. Methods}

Based on the investigation of the current App music game, according to adolescents the physiological and psychological characteristics of adolescents (12-14 years old) develop test plan and scheme. Focus on the survey of the research object from the following aspects: 1 . basic knowledge and basic skills; 2. processes and methods; 3 . emotional attitude and values; 4. physiological and psychological characteristics. In the course of the experiment, no other support App music game of the new media, only the use of smart phones App experiment.
Survey questions divided into four individual, every project and concrete expansion for a number of sub projects: knowledge and skills ( acoustic perception, music creation, music culture, music appreciation, hearing, visual association), process and method (music information collection and collation and induction, cooperative inquiry), emotional experience (attitudes and values, cooperation and coordination ability, physiological and psychological characteristics (thinking characteristics, behavioral characteristics). Picking selected and Q\&A way carries out subject of individual survey to those selected App music game. The object to be measured is to identify the survey questions, understanding, and operational awareness. Results were classified into ABCDEF level, ABCDEF level to 5, 4, 3, 2, 1, 0 points.

\section{ANALYSIS OF THE RESULTS OF EXPERIMENTS}

\section{A. Comparison of Experimental Group and Control Group on the Total Score of Music Cognition and the Process of Obtaining Music}

The results of the histogram are shown in the experimental group in the visual association and control group had the same score, the total score of other items are all more than the control group "Fig. 1".

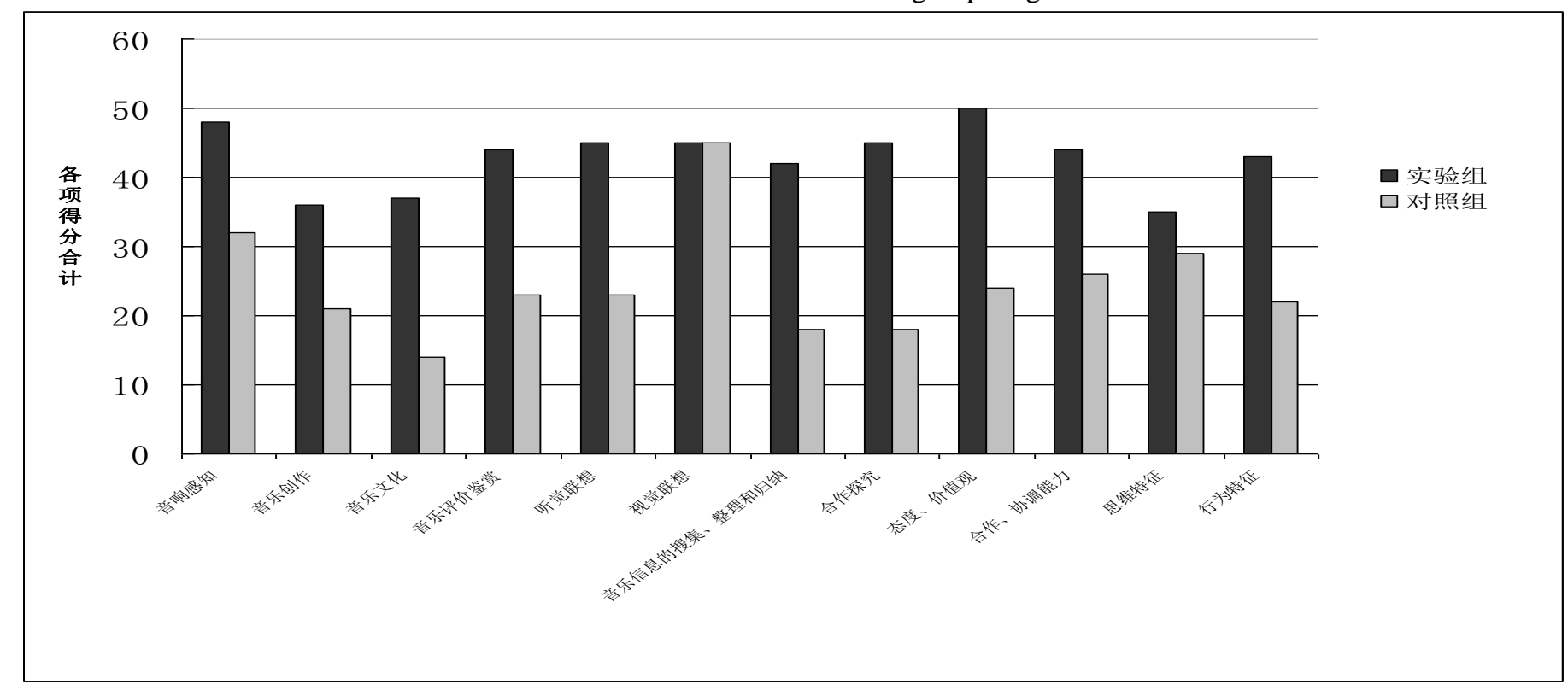

Fig. 1. A histogram of music cognition of the youth (12-14 years old) based on App music game and their acquisition process scoring

According to the common calculation method through the test result data of measurement, respectively sum, it is concluded that the experimental group and control group $\mathrm{x}$ (on average) respectively 34.2, 19.7, s (annotation errors) respectively $3.87,2.44$, (difference significance level $\mathrm{P}<0.01$, showing the total scores of the experimental group and control group were significantly different. ( $P$ value is used to determine a parameter to the result of hypothesis testing, when $\mathrm{p}<0.01$ identified with significant difference, $\mathrm{P}<0.05$ identified as significant difference, $\mathrm{P}>0.05$ identified no significant differences) by $\mathrm{F}$ (homogeneity) of variance test prove two general variance homogeneity, and significant differences in the total scores of the two groups is caused by the difference of the average number of nature. Conclusion: the overall music cognition and acquisition process is better than the control group, often involved in Music App game of adolescents in music cognition and acquisition process is better than never participate in Music App game of teenagers. 


\section{B. Comparison of the Individual Performance of the Experimental Group and the Control Group in the Process of Music Cognition and Acquisition}

Through data processing, a single sum, the experimental group and the control group of individual $\mathrm{x}, \mathrm{S}, \mathrm{P}$. Sound apperception: $\overline{\mathrm{X}}(2.47,0.93), \mathrm{S}(0.81,0.68), \mathrm{P}<$ 0.01 ; Appreciation of music : $\overline{\mathrm{x}}(2.93,1.53)$, S (0.44, $0.62), \mathrm{P}<0.01$; Auditory association $\overline{\mathrm{x}}$ (3.0, 1.53) , $\mathrm{S}$ $(0.63,0.62), \mathrm{P}<0.01$; Visual association : $\overline{\mathrm{x}}$ average 3.0, $\mathrm{P}>0.05_{-}$; Collection and arrangement of music information : $\overline{\mathrm{x}}(2.8,1.2), \mathrm{S}(0.65,0.54), \mathrm{P}<0.01$; Cooperative inquiry : $\overline{\mathrm{x}}(3.0,1.2), \mathrm{S}(0.37,0.4), \mathrm{P}<$ 0.01 ; Attitudes and values : $\overline{\mathrm{x}}(3.33,1.6)$, S (0.6, 0.49), $\mathrm{P}<0.01$; Cooperation and coordination ability : $\overline{\mathrm{x}}$ $(2.93,1.73), \mathrm{S}(0.25,0.44), \mathrm{P}<0.01$; Thinking characteristics : $\overline{\mathrm{X}}(2.33,1.93), \mathrm{S}(0.70,0.77), \mathrm{P}<$ 0.01 ; Behavior characteristics : $\overline{\mathrm{X}}(2.87,1.47), \mathrm{S}$ (1.02, 0.62) , $\mathrm{P}<0.01$; gender difference : $\mathrm{P}>0.05$.

Data showed that there was no significant difference (P > 0.05 ) except for the visual association and gender difference, and the difference was significant $(\mathrm{P}<0.01)$. The experimental group was significantly better than the control group.

\section{EXPERIMENTAL RESULTS}

The study of music cognition and its acquisition process are important parts of the practice of music education, and the experimental study shows that the experimental group has outstanding advantages in knowledge and skills.

\section{A. Sound Perception, Music Creation}

Experimental group has a positive reaction on the pitch, tempo, rhythm, timbre and other basic cognitive abilities through the practice of music App game, not only develop and improve the sound perception ability through independent practice for the juvenile, but enhance content understanding and emotional experience of songs, dance, appreciation and rhythm. Based on experimental group of sound perception, creation of musical elements and structures, and expression of music creation ability through action have significantly improved.

\section{B. Music Culture}

The cultural values of the experimental group are significant. Understanding the relationship between music and history and culture, and understanding the relationship between music and other disciplines outside are not only the main content of the national music course standard, but similar to our country's music curriculum standard which advocates comprehensive disciplines, carries forward the national music and understands multicultural content requirements. Music App game collection of music, dance, drama, film, art and other forms of art embodies a concentrated reflection of the music elements and different types of art elements, it is because of such a comprehensive collection of art form and elements that teenagers must consciously or unconsciously to accept, understand, excavate and disseminate these art elements of knowledge and skills in practice. Not only that, game music mostly selects typical Chinese and foreign music as the source material, no matter which form of music game, it must have association with national classic, excellent and popular music because of the music content selection of typicality and popularity. Furthermore, music game exerts a subtle influence on music culture: on one hand, the spread of our national outstanding traditional music not only deepens the understanding and love of teenagers, but enhances national consciousness and the sense of patriotism. On the other hand, in the dissemination of national music culture, adolescent's cognitive vision gets wide, learning, understanding and respecting other countries and nations of the world music culture ability cultivation and promotion, which is not only conducive to the teenagers to establish equal multicultural values, but beneficial to share in the development of multi culture of all outstanding artistic achievements.

\section{Appreciation and Evaluation of Music}

Experimental group has a strong comprehensive appreciation and evaluation ability. Openness and special commodity characteristics of App music game for all young people determine adolescence to have no restraint and independent evaluation and appreciation attitude, which not only extends musical individuality of young people, but improves their music evaluation and power to appreciate. In addition, the basic idea which music aesthetic is the core gets effective, music curriculum standard emphasized, throughout through the youth appreciation of music App game, and youth music basic knowledge and basic skills dynamically infiltrate in the appreciation experience, which not only increase the ability of music and aesthetic features for teenagers, but guide the young people to grasp of overall musical forms and emotional connotation to understand the musical elements in music performance.

\section{Auditory Association:}

Experimental group has a strong ability of synesthesia. Synesthesia is called psychological phenomenon that stimulates the sensation of other senses in a sense organ by psychologists. In music App game, developers do their best to pursue music content beauty, therefore, sound synesthesia zoom in to the extreme without reservation greatly stimulate young people's auditory system, so as to produce auditory experience. At the same time, with App game music scene and adolescents skills of eurhythmics, further make teenagers synesthesia to some sort of emotional experience and a variety of perceptual features, resulting in emotional experience, auditory association. Through the research of visible, Music App game music synesthesia mainly reflects through the following six aspects: first, relationship with pitch experience synesthesia (the sound frequency, the modality of height, visual experience, spatial perception, the mass of the body, the shape of the object and the volume of the motion state of the object). Second, relationship with intensity experience synesthesia (sound, all kinds of things, the energy and strength, the object of the object shape, weight, modality of experience, space distance). Third, the corresponding synesthesia relationship with speed, rhythm (sound, spatial extension, object size, object weight, individuality and personality 
characteristics, the movement of things, emotion and attitude, communication behavior). Fourth, corresponding synesthesia and pronunciation time (voice, touch, communicative attitude and personality, decision-making and behavior, and determine the relationship between visual modality, survival). Fifth, corresponding synesthesia and tension (voice, modality, color, visual interest and the need of subject, personality, cognition, touch). Sixth, the corresponding relationship between sound effects, visual perception, thinking activities, social life and natural events.

\section{CONCLUSION}

On account of App music make the development of basic music knowledge and basic skills of the juvenile, its representations are that the basic skills of music performance get consolidate and improve; music appreciation of the range has been expanded; cultural awareness of music get establishment; music perception and appraisal connoisseurship ability get improved; good music appreciation habits can be initially cultivated; music performance ability is developed, and artistic imagination and creativity get rich. In addition, in the process and method of the experiment, music information collection, induction and finishing ability of the experimental group was significantly better than the control team, and explored the application of music through the way of cooperation. In the emotional experience of the experiment, the experimental group reflects the basic music appreciation habits, optimistic attitude, group awareness, cooperation and coordination ability, which are better than the control group. In physiological and psychological experiments, experimental group reflects certain abstract logical thinking ability, the significant feature of logical thinking, physiological and psychological maturity better than that of the control group (expressed in terms of the characteristics of psychological development contradictions: the sense of participation, hope of getting respect, the voice changing period). Therefore, this research draws the following conclusions:

- App music game has a positive effect on youth music cognitive vision broadening and musical ability development.

- In the cognitive structure of music, the knowledge and skills of young people who often involved in music App game has prominent advantages, especially in the sense of sound, music creation, music culture, music appreciation and hearing association, but gender difference is not significant.

- Our current music education system in middle school should be strengthened, such as the change of adolescent physical and psychological characteristics and realistic environment in concept, attitude and methods consider some changes. For example, take appropriate monitoring of the App music game teenagers, minimize its negative impacts, use maximum of positive factors to play its positive impact.

\section{REFERENCES}

[1] Ministry of Education, Curriculum Standard of Music for Full-time (Trail Edition) [M], Beijing: Beijing Normal University Press, 2001.

[2] Ministry of Education, Curriculum Standard of Music for Full-time (Trail Edition),reading, [M], Beijing: Beijing Normal University Press, 2002.

[3] Zhang Qian, Music Aesthetic Tutorial, [M], Shanghai: Shanghai Music Press, 2002, 108-117.

[4] Zhou Shibin, Music Education and Psychology Research Methods, [M], Shanghai: Shanghai Music Press, 2006, 241-294.

[5] Zhou Shibin, Gong Zheng, Study and Analysis of Music Education in Foreign Literature, [M], Shanghai: Shanghai Music Press, 2007, 6-13.

[6] Yin Aiqing, Introduction to School Music Education and Materials and Teaching Methods, [M], Beijing: People's Music Publishing House, 2010, 34-65. 